\title{
Forma y vacío en la poesía de Severo Sarduy
}

\author{
Sandra Lucía DÍAZ GAMBOA \\ Facultad de Ciencias Sociales y Humanas \\ Universidad Tecnológica de Bolívar \\ sdiaz@unitecnologica.edu.co
}

\begin{abstract}
RESUMEN filológicas y filosóficas de dicha correlación. ideogramas, inestabilidad, espacio.

[Recibido, junio 2012; aprobado, diciembre 2012]

\section{Form and void in Severo Sarduy's poetry}

En el presente artículo vamos a elevar modelos sobre los modelos y/o figuras simuladas en la poesía de Sarduy que, nos pueden revelar la relación entre la forma y el vacío y, las implicaciones

Palabras clave: Barroco, simulación, infiniversión, vacío, anamorfosis, forma, expectroversión,

\begin{abstract}
In this essay we will elevate models on simulated models and/or figures in Severo Sarduy's poetry which can reveal the relationship between form and void and the philological and philosophical implications of that correlation.
\end{abstract}

Keywords: Baroque, simulation, infiniversión, void, anamorphosis, form, expectroversión, ideogram, instability, space. 
En los modelos arquitectónicos y/o cosmológicos que simula Sarduy podemos descubrir una importante relación entre la forma y el vacío que tiene implicaciones filológicas y filosóficas; esta correlación la vamos a investigar por medio de los modelos poético-matemáticos de la infiniversión ${ }^{1}$, la expectroversión, la estética de la evanescencia ${ }^{2}$, que hemos creado y, del sistema leibniciano.

Sarduy arma sus modelos a partir de la simulación de los modelos de la arquitectura barroca, Borromini; la astronomía, Kepler; el barroco español, Góngora; el neobarroco, Lezama; los fenómenos pictóricos de la anamorfosis y el trompe-l'oeil; la astrofísica del siglo XX; la Action painting; la geometría proyectiva y las figuras del cubo, la elipsis, la espiral, los polígonos, etc. Modelos y figuras que se reflejan, desdoblan y desvanecen en el espacio que se expande en el volumen de los poemas:

POLÍGONOS de estuco. Cúpulas que en el agua reflejan. A cada cuerda tiembla la superficie, a cada voz en el rectángulo de la alberca se desplaza un instante la sucesión de arcos, de salas que se abren al jardín, de jardines idénticos que interrumpen albercas, rectángulos espejeantes, agua inmóvil donde a cada voz, a cada cuerda se reflejan un instante, desaparecen, se reflejan otra vez los vacíos polígonos de estuco, las cúpulas, madera y nácar, la invariable sucesión de los arcos, el orden de las salas sonoras, los jardines florecidos, húmedos, abandonados, saqueados, devastados, quemados. olvidados, ruinas, sueños, cenizas(Sarduy 1974a:9).

Estamos ante un teatro catóptrico que proyecta dramática e infinitamente la duplicación de un instante especular. La pulsión de la repetición de algo desconocido e inalcanzable se relaciona con la muerte. El símbolo de las cenizas, alude a la nada en que se sostienen todas las formas. Este fragmento con que se abre el libro de poemas Big Bang constituye una alegoría del barroco fúnebre, "el tormento de una finalidad en la profusión" (Barthes 1973: 132).

Los poemas de Sarduy abren y multiplicanel espacio, proyectanla sucesión cinematográfica de la escritura y,reflejan la teatralidad de los signos que, retoman de la arquitectura barroca: "POLÍGONOS de estuco. Cúpulas que en el agua reflejan [....] ]otra vez los vacíos polígonos de estuco, las cúpulas, madera y nácar,/ la invariable sucesión de los arcos, el orden de las salas sonoras, los jardines /florecidos."

Las experiencias curvilíneas y virtuosismos matemáticos del Barroco se inician con Pietro da Cortona, quien crea un espacio de dimensiones y direcciones múltiples e introduce la elipse en el peristilo de Santa Maria della Pace; Borromini continua, perfila en elipse todo el patio interior de la Sapienza, hace alternar en paredes convexas y cóncavas el campanario de San Andrea della Frate, corona con una espiral helicoidal el de la Sapienza: constituye, con la primera oleada del estilo barroco, la realización efectiva del paralelismo imaginado por Spengler entre la Matemática y la Arquitectura de una época, la invasión de la cinemática, de la astronomía kepleriana y luego de la Geometría

\footnotetext{
${ }^{1}$ El descubrimiento y el desarrollo de los conceptos de infiniversión y expectroversión en la literatura se encuentran en la Tesis doctoral de S. Díaz Gamboa, La experiencia de los límites en la obra de José Ángel Valente y sus "implicaciones" lógico-matemáticas, pp.90- 1700. Y, la síntesis de estos conceptos, en el ensayo de la misma autora, titulado, "La formación de conceptos poético-matemáticos en la obra de José Ángel Valente", pp. 56-80.

2 "La Estética de la Evanescencia" es un concepto descubierto y desarrollado por S. Díaz Gamboa en la Tesis de Maestría, titulada "La Estética de la Evanescencia" en Blanco de Octavio Paz.
} 
analítica en el dominio dela morfología estética. En esta atmosfera, además de la elipse, la espiral está especialmente de moda y, en esto, los arquitectos aventajan a los mismos geómetras.

Un tiempo después no bastan los puntos de inflexión y de retroceso, ni el símbolo curvilíneo - espiral o sinusoidal- de la exponencial, de la pulsación logarítmica, ni la ondulación de las fachadas inauguradas por Borromini en su pequeña iglesia de San Carlino. Es el volumen mismo lo que los virtuosos de esta segunda fase del barroco se ingenian en diferenciar o integrar como las aguas de una ola que se rompe y se rehace. Como el Cálculo Integral y Diferencial de Leibniz, y como el volumen que la poesía de Sarduy traduce como el crecimiento de la danza:

Un cubo despegado.

Pegada la oreja a la pared.

Oye.

Algo va a romperse. Algo

crece.

Lo que en el muro

Hierve. (Sarduy 1974a: 102).

El texto se presenta como un espacio musical en el que tenemos un despliegue lineal de un acorde vertical (Díaz 2010: 32). En este espacio los sonidos tienen cualidades de densidad y volumen, es decir, texturas: despegado, pegada, pared, romperse. Romperse, crece, hierve. Y podríamos decir que estos diseños evolucionan en conceptos como la condensación, el estallido y la vacuidad.Transitamos desde la materialidad vibrante de lo verbal, fulgor, latido, animalidad hacia complejas arquitecturas sonoras y conceptuales.

La letra "p" sufre una torsión, adquiere un grosor y en esto involucra el desbordamiento de la luz, de la sombra y del sonido que hierve. La infiniversión de esta masa de sonido venido del espacio nos envuelve en el volumen de su musicalidad. Empresa un tanto similar a la que realiza Roman Jakobson en la lingüística y poética debido a la fuerte influencia que recibe de la pintura moderna desde muy joven. Basta mencionar su fecunda amistad con Malevich, del cual toma la idea de arrancar la letra de su línea única para alcanzar la distribución de las masas de letras-sonidos en el espacio:

Llegados a la idea del sonido, tuvimos las notas-letras que expresan las masas fónicas. Tal vez se podría hallar un nuevo camino en la composición de estas masas fónicas (expalabras). De esta suerte, arrancamos la letra de su línea, de su dirección única, y le damos la posibilidad de moverse libremente...Por consiguiente, llegamos a... la distribución de las masas de letras-sonidos en el espacio, tal como el suprematismo en pintura. Estas masas quedarán suspendidas en el espacio y procurarán a nuestra conciencia la posibilidad de adelantarse cada vez más lejos de la tierra". (Jakobson 1981: 176).

Esto nos hace pensar en la línea flotante y cósmica que anima la poesía de Sarduy, en la cual las moléculas o estructuras auditivas se unifican con el origen de su disposición tipográfica produciendo el volumen del poema.

El cubo aparece como el soporte de toda forma posible. El cubo, la unidad espacial mínima, es análogo al texto blanco, son los cuerpos primeros de una potencia verbal, las pulsaciones exponenciales y los volúmenes que introducen un crecimiento que ya no es únicamente vertical, sino que sugiere la exuberante expansión de los organismos mari- 
nos o la recursividad del pensamiento, el cuerpo es una máquina/ dentro de un cubo blanco (Sarduy 1974a:19).

El lenguaje pone en escena las cosas, el pensamiento mismo. Auto-conciencia que puede ser pensada como una transformación topológica a escala cósmica en donde ha sido curvado el volumen de la página en todos sus puntos y no sólo la superficie que la limita o representa.

La página conjetura otra dimensión para obtener precipicios y caídas, el espacio se piensa y se deforma continuamente hasta que lo inferior se adhiere a lo superior y la derecha a la izquierda. Ello, sin embargo, significa que lo puede seguir considerando como un plano. Por lo tanto las imágenes geométricas de los poemas son el resultado de la intersección, en un plano, de una figura correspondiente que posee además otra dimensión, como el cuadrado (de los estanques) resulta de la sección de un cubo, o el círculo de la de una esfera. Los signos poéticos son secciones de otras dimensiones.

Esta topología hace pensar en una geometría elíptica donde todos los "puntos", "líneas" y demás tienen que ser parte de una esfera común, donde un punto consiste en un par de puntos opuestos diametralmente sobre la superficie de la esfera y una línea es un gran círculo sobre la esfera ${ }^{3}$.

Esta superficie es finita pero ilimitada, tiene la forma de tautología representada por los gramas sintagmáticos que implican la condensación de secuencias que opera la lectura, desciframientos parciales y progresivos que avanzan por contigüidad y nos remiten retrospectivamente a su totalidad. Los indicadores, presentes en el encadenamiento de las secuencias o en las articulaciones interiores a estas, en las unidades mayores y masivas del discurso que, hacen referencia a la gramática que la sostiene, al código formal que le sirve de cimiento, de apoyo teórico, al artificio reconocido que fija el soporte irreductible:

DENTRO DE UN CUBO BLANCO
UN VOLUMEN FICTICIO
LA PÁGINA ES UN CUBO
CÓMPLICE DE LA MIRADA
TODO CUERPO ES UN CUBO
VOLÚMENES DE OCRE
TODO CUBO UNA ESFERA
SUPERFICIES GRISÁCEAS
TODO CUERPO CONVIERTE
DENTRO DE UN CUBO BLANCo
SUS ARISTAS EN OTRO dentro de un cubo blanco
el cuerpo un cubo blanco
enarbola sus cajas

(Sarduy 1974a: 18).

El encajonamiento de los cubos de la escritura y el cuerpo funciona infinivertidamente, en un espacio reversible en donde la mirada que mira funciona también "antes", "atrás", en la que se mira en esa mirada.

\footnotetext{
${ }^{3}$ En la geometría elíptica del universo la línea más perfecta y rectilínea es una curva de 30.000 años luz que vuelve sobre sí misma, como todas las rectas, porque el espacio mismo es curvo.

Las líneas rectas trazadas sobre la superficie de la tierra son siempre parte de un círculo máximo y aun cuando dos de dichas líneas sean perpendiculares a una tercera-lo cual en la geometría euclidiana significaría que son paralelas- siempre se cortarán en un par de polos (Penrose 1995: 268-273)
} 
En el cubo vacío del poema somos poseídos, desengendrados e invinivertidos para nacer en otro cubo silenciado, "TODO CUERPO ES UN CUBO / dentro de un cubo blanco".

Con esto podemos decir, geométricamente, que tenemos, en el poema, dos cubos anidados, tal como lo podemos imaginar más abajo:

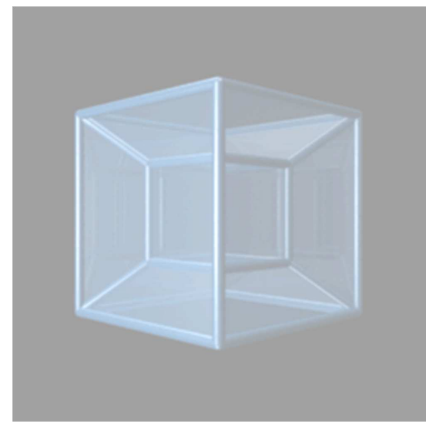

Estructura Infinivertida

El sonido, la materia, la escritura, el espacio y la lectura de los poemas son infinivertidos ya que, el volumen tipográfico del sonido o la unidad de la topología sonora de las letras crea un cubo vacío que anida otro cubo de silencio (Díaz 2008: 1214).

Estamos ante figuras de figuras que remiten a propiedades de propiedades (duplicidad, simulación, serialidad, cromaticidad, infinitud, vacuidad) que pertenecen a una lógica de por lo menos segundo orden ${ }^{4}$. La épure de la escritura ${ }^{5}$, su diagrama y su decantación nos acercan a los teoremas de representación de Freyd. Estos teoremas apuntan, entre otros, a los siguientes aspectos - que podamos asociar en cierto modo a rasgos similares en la poética de Sarduy y seguramente a lo hecho por Mallarmé-: representabilidad: la obra se ve como un tejido relacional, con inmersiones y demarcaciones sígnicas; universalismo: la obra se basa en esquemas abstractos (generales)- como el cubo-, antes de ser contextualizada (concretizada); constructivismo: la obra requiere de un montaje a la vista para que el lector detecte y complete su construcción ${ }^{6}$.

La dinámica de la estructura infinivertida de los cubos anidados en la poesía de Sarduy es afín a la que encontramos en la obra de Cezanne, para quien es preciso reducir las formas "al cubo, el cilindro y la esfera"(Barros 2001: 80); con tal propósito, las imágenes se hacen fluctuantes y sincopadas, como en la poética que estudiamos: "dentro de un cubo blanco//VOLUMENES DE OCRE / TODO CUBO UNA ESFERA//el cuerpo// SUPERFICIES GRISÁCEAS." Las imágenes varían dentro de un mismo ritmo, expectrovertidamente, adquieren un valor cromático:

\footnotetext{
${ }^{4}$ Con la lógica de predicados aparece la distinción entre predicados de primer orden - cuyos argumentos son objetos - y de segundo orden, cuyos argumentos son predicados de primer orden (Díaz 2008: 327).

${ }^{5}$ La épure en el sentido de tránsito semántico que se descubre, según H. Costa, entre proyecciones/decantaciones; dibujos/purgaciones; trazos/refinamientos; elevaciones/eliminaciones (Costa 1991: 275300).

${ }^{6}$ Para profundizar sobre estos aspectos de la Teoría Matemática de Categorías y el impacto extraordinario de ésta sobre las matemáticas contemporáneas Vid. Zalamea, Fernando, Signos Triádicos, 180- 190; Ariadna y Penélope. Redes y mixturas en el mundo contemporáneo, 8-9.
} 
A la luz amarilla aparecen un instante, se borran, superpuestos a sí mismos, divididos por una falla negra, los volúmenes de ocre, los cuerpos vacíos que lo negro, la sombra espesa sobre la página tacha, deja ver un instante más hasta que la luz amarilla, limón, ópalo, vidrio de orine, acecho de ojos de tigre vuelve a descubrirlos, a extraerlos del fondo de la página, de la noche de tinta, a rescatarlos para la efímera simetría que ordena una línea, que divide una falla negra a cuyos lados se equilibran cuerpos de ocre, volúmenes vacíos que esplenderán un instante, estampados de amarillo, día estriado,salto, azufre, tigre. (Sarduy 1974a:18).

La expectroversión, -la luz amarilla, limón, ópalo, la noche de tinta-, es producto del recubrimiento de las tinturas en un continuo cromático y musical que reconstruye una dimensionalidad que está más allá, "el poema proyecta la larga cromaticidad del vuelo de las palabras, conjuga los restos, las sombras y los límites en la modalidad de lo posiblemente imposible: entraren lo gris, en la memoria, en el canto" (Díaz 2008:443). El valor topológico de este continuo cromático-musical nos recuerda la ciencia combinatoria de Leibniz.

El arte de la combinatoria se centra en el arte de descifrar. Leibniz identifica el criterio de la semejanza con el de la "expresión" de las similitudes que se reconocen en una "invariante" a pesar de las mayores deformaciones. Éstas son sus palabras: "No es necesario que lo que concebimos de las cosas extramentales sea completamente semejante a ellas, sino que las exprese, como una elipse expresa a un círculo visto de través" (Leibniz 1982:160). Con esta idea Leibniz destaca el valor de la cualidad sobre la métrica. Anticipa así lo que será la Topología ${ }^{7}$, la cual se ocupa de aquellas propiedades de las figuras que permanecen invariantes cuando dichas figuras son plegadas, dilatadas, contraídas o deformadas de cualquier manera, tal que "no aparezcan nuevos puntos o se hagan coincidir puntos ya existentes" (Kline 1992:1529).

Con la propiedad de invarianza, Leibniz, propone, a su vez, una teoría del conocimiento, el cual "no consiste en la identidad del pensamiento con la realidad, ni en cierto 'parecido' o 'semejanza' entre el primero y la segunda, sino en que el pensamiento 'exprese' la realidad" (Leibniz 1982:160).

Con el reconocimiento de la figura invariable que se conserva a través de toda la diversidad de los reflejos, las nociones cualitativas se muestran como esenciales, donde lo cuantitativo es el accidente; la noción de orden aparece, matemáticamente, más profunda que la noción de medida. ${ }^{8}$

Leibniz se revela como el primer "formalista", el primer matemático del orden y de la cualidad, anticipa la topología y recupera, como Sarduy, el problema del infinito y sus especificaciones: series, convergencia, paso al límite, "a cada voz en el rectángulo de la alberca se desplaza/ un instante la sucesión de arcos, de salas que se abren al jardín, de jardines/ idénticos que interrumpen albercas, rectángulos espejeantes, agua inmóvil/ donde a cada voz" (Sarduy 1974a:9). El poema dibuja la espiral que toca en una infinidad de puntos una multitud de curvas, "los vacíos polígonos de estuco, las cúpulas, madera y nácar, la invariable sucesión de los arcos, el orden de las salas sonoras, los

\footnotetext{
${ }^{7}$ Tenemos en la historia de las matemáticas la profética afirmación Leibniciana que podría servir de detonante metafórico en los estudios filológicos: "Creo que nos falta otro tipo de análisis propiamente geométrico que exprese directamente la localización, así como el álgebra expresa la magnitud”. Citado en Kline, Morris, El pensamiento matemático, v.III, 1529.

${ }^{8}$ Para un análisis del formalismo en Leibniz, véase Serres, Michel, La comunicación, 156.
} 
jardines florecidos". La escena del poema descubre la serie convergente de todas las series (Díaz2008: 249), la curva de variable única, la voz, "hasta que el hilo estridente se pierde entre las manchas de musgo,/ siguiendo una línea de puntos"(Sarduy 1974a: 13).

En la poesía de Sarduy son frecuentes las series de la escritura, de los tintes o los colores, del cuerpo, de la geometría, de lo arquitectónico y de lo musical, y las series de estas series:

un triángulo de estratos

$$
\begin{aligned}
& \text { SE LE FUE EL AZOGUE } \\
& \text { tablado verde }
\end{aligned}
$$

mármoles divergentes

COMO ESCRIBIR EN AGUA

el cuerpo gira

un prisma la cabeza

$$
\begin{aligned}
& \text { QUE ESTÁ EN LO ALTO DE LA TORRE } \\
& \text { sobre lentes mojados }
\end{aligned}
$$

el cuerpo es una máquina

CON LOS DÍAS DE, INVIRRNO

la picrna una belice

en equilibrio estable

UN LETRERO QUE DICE

relojería blanca

(Sarduy 1974a: 21)

Series de la escritura y la metaescritura: SE LE FUE EL AZOGUE, COMO ESCRIBIR EN AGUA, UN LETRERO QUE DICE.

Series de los tintes y colores: tablado verde, relojería blanca.

Series del cuerpo: el cuerpo gira, un prisma la cabeza, el cuerpo es una máquina, la pierna una hélice.

Series de lo geométrico: un triángulo de estratos, mármoles divergentes, la pierna una hélice.

Series de lo arquitectónico: tablado verde, mármoles divergentes, QUE ESTÁ EN LO ALTO DE LA TORRE, en equilibrio estable.

Series de lo musical: ALTO, TORRE.

Las series sonoras de las palabras nos entregan la operación del paso al límite (la ósmosis musical de los fonemas) y su convergencia tiende a alcanzar $\mathrm{n}$ dimensiones:

Triangulo, estratos, tablado, divergentes, está, alto, torre, lentes, estable, letrero

Mármoles, como, prisma, mojados, máquina

Verde, invierno, pierna

Las series de las series dibujan el ideograma de la escritura, un triángulo de estratos. La disposición de los signos nos revela un sistema de relaciones secretas, construido como un objeto cubista, al modo de los poemas que crea Reverdy al transformar "las sensaciones y los sentimientos mismos en objetos" e inmovilizar el instante?

\footnotetext{
${ }^{9}$ Subraya O. Paz que en los mejores poemas de Reverdy el tiempo posee una extraña viveza: “....Pero es un tiempo enjaulado, un tiempo que no transcurre...Reverdy es uno de los poetas más intensos de este siglo; también es uno de los más monótonos"(1987: 178).
} 
Universo textual en el que las frases tienden a configurarse en centros más o menos independientes, creando sus propios dominios y a veces fundiéndose en la página como soles encerrados: desplegando el desierto.Proyección inestable, constelación incierta. Movimientos de contracción y expansión. Simultaneísmo.

Derivado del cubismo aparece el orfismo, en que se manifestó el simultaneísmo en pintura $^{10}$. En poesía, el simultaneísmo fue desarrollado por Pound quien, al modo de Sarduy o de O. Paz, presenta las imágenes como "constelaciones de signos, ideogramas en movimiento" 11 . Los poemas de Sarduy enfatizan redes, develan esqueletos conceptuales, descubren pliegues, escalan diagramas. Entre los símbolos se da una plena correlacionalidad abstracta: tránsitos, reflejos, simetrías, inversiones, refracciones, difracciones, recursiones, etc. Un tejido de relaciones que permite aproximarse a la universalidad.

El carácter ideogramático de los poemas de Big Bang nos recuerdan el lenguaje de la lógica simbólica, el cual no sólo elimina irrelevancias; ya que lo más importante se encuentra, según James Newman, en la "sugestión" de los símbolos que permiten "apreciar materialmente simetrías, relaciones y semejanzas que quedan ocultas o veladas en el lenguaje ordinario"(1983: 241). Y se puede descubrir el esqueleto de las expresiones de aspecto parecido que pudieran ser sustancialmente equivalentes, ya que "la esencial vinculación interna de las significaciones, se manifiesta mediante una determinada disposición de ideogramas bien hechos"12.

En la danza icónica de los poemas también es factible hablar de la disposición de los "ideogramas" en su vinculación con las significaciones, de simetrías sonoras y de esqueletos conceptuales; de la infiniversión de la forma y el pensamiento, tal como sucede en la Característica leibniciana (Díaz 2008: 238). La Característica reconduce toda disciplina a los signos, para que así pueda colaborar activamente la imaginación. Los caracteres operan como marcas sensibles en una escritura ideográfica que representa directamente los pensamientos.

Triángulo de estratos, simultaneísmo y transposición que alcanzan la transparencia. Infiniversión. Las hendiduras, los blancos, los paréntesis, la disposición tipográfica, el tiempo verbal, el condicional, son las maneras de crear entre frase y frase la distancia necesaria para que las palabras se reflejen en un espacio vacío.

En la convergencia del movimiento, -el cuerpo gira, la pierna una hélice-,el arco apunta más allá del blanco; se trata de la armonía que tiende en direcciones opuestas, mármoles divergentes. Mármoles divergentes que trasfieren la imagen de la opacidad de las palabras de cal apagada, pasta o mármol pulverizadoque simbolizan la relación

\footnotetext{
${ }^{10}$ Nos explica O. Paz que "En el orfismo había elementos simbolistas -la idea de la correspondencia universal- y afinidades indudables con el hermetismo del abstraccionismo, tal como lo concebía Kandinsky" (1987: 179).

${ }^{11}$ Los escritos de Paz sobre Pound son una muy buena descripción de lo que acontece en Big Bang: "El sistema poético de Pound consiste en la presentación de las imágenes como racimos de signos sobre la página ideogramas, no fijos, sino en movimiento, a la manera de un paisaje visto desde un barco o, más exactamente, tal como las constelaciones forman distintas figuras a medida que se juntan o separan sobre la hoja del cielo. La palabra constelación evoca inmediatamente la idea de música y la de música con sus múltiples asociaciones, del acorde erótico de los cuerpos al acuerdo político entre los hombres, suscita el nombre de Mallarmé” (Paz 1987: 197).

${ }^{12} \mathrm{Y}$ sobre el valor de lo icónico en el pensamiento, agrega Newman: "Un simbolismo eficaz pone de manifiesto errores antes no percibidos, y sugiere además nuevas implicaciones y conclusiones, nuevas y fecundas líneas de pensamiento"(1983: 241).
} 
entre la dispersión y la condensación o el pliegue ${ }^{13}$, que traduce la problemática central de la forma y el vacío ${ }^{14}$; la dispersión de la materia de las palabras que da cuerpo a los silencios, asilo a las esperas. La gravidez y aceleración de las palabras potencian extensiones sensibles. Contemplamos la yuxtaposición de diversas texturas, de vetas opuestas. Equivalente a la puesta en escena del soporte de la propia operatividad donde la escritura perturbada se refleja y refleja el poema, el Universo. Lo impensado contiene el pensamiento;doble que está inscrito en la diacronía del volumen. Densidad del sentido que ha sido examinada por el propio Sarduy en el fenómeno de la duplicación:

El modelo y el ícono que lo imita, que intenta duplicar su verdad, su identidad última, son relegados, postergados en un mismo registro de exactitudes y fidelidades: esas que abandonan o desprecian, fascinantes en el espejeo de su inmovilidad, en el rapto de los atributos visibles, los adeptos de la exhibición y el juego, los convertidos en el soporte que los mantiene, los adictos a la invisibilidad: ilusionistas y simuladores (Sarduy 1982: 18-19).

El desajuste de las significaciones consiste en formas y vacío: los signos quedan aislados por distancias imprevistas, con rasgos de variabilidad, y ocupan sitios variables, tras la rotación de un ángulo recto colocan su figura en la línea del discurso, para distenderla y dispersarla en vacuidad simultánea a sí. Escenario de la escritura, espejo ${ }^{15}$ del texto y de la figura sobre él.

Estamos en el espacio con palabras diagramáticas, en un espacio en el que gravitan algunas palabras. El espacio es un campo vectorial de flechas que indican el sentido, ya se trate de todos los sentidos de este espacio globalmente considerado o de un solo sentido, considerado localmente, COMO ESCRIBIR EN AGUA.

La circulación de las palabras traza líneas de campo en el vacío: flechas paralelas o líneas que giran o retroceden. Simetrías de traslación, rotación y reflexión,

El cuerpo gira

un prisma la cabeza

TORRE

QUE ESTÁ EN LO ALTO DE LA

lentes mojados

sobre

La ordenación expectrovertida de los versos convierte, subvierte lo unívoco, es una versión de lo universal. El modelo espacial designa la inclinación, la caída y el torbellino delas palabras. El sentido aparece sobre el trasfondo. De una traslación a la otra tiene lugar la traducción.

En general el modelo de la expectroversión, en la poética de Sarduy, implica la posibilidad universal de traducir los temas (deseo, desaparición, etc.), a lo cual se agrega la posibilidad universal de hacerlos variar en sí mismos para dar cuenta de su forma-

\footnotetext{
${ }^{13}$ Para un acercamiento a los problemas filosóficos que plantea el concepto de "pliegue" véase Deleuze, Gilles, Diferencia, El Pliegue.

${ }^{14}$ Una investigación profunda sobre los aspectos estéticos y vitales del vacío requiere la lectura indispensable del Tao te King de Lao Zi y Vacio y Plenitud de Francois Cheng.

${ }^{15}$ Los espejos son umbrales que nos transportan de lo virtual a lo real, en la manipulación de los canales, el fenómeno de la congruencia y la producción del doble.
} 
ción. La traducción puede pensarse como una versión del paso al límite, otro "resplandor de la nada" (Sarduy 1982:112).

En el paso al límite, del sistema leibniciano, la integración de la serie tiende a un límite y siempre es posible intercalar otro término entre la suma y un límite: el orden de las salas sonoras,...., los jardines florecidos, húmedos, abandonados, ...,saqueados, devastados, quemados, ..., olvidados, ruinas, sueños, cenizas.

En el interior de un mismo orden se presenta una variada escala de órdenes donde un elemento cualquiera es infinitamente pequeño o infinitamente grande en relación con el elemento que lo precede o le sigue. Así las cenizas tienen su peso y su gravedad. El pensar la operación de paso al límite nos lleva, de nuevo, al estudio de las series y de su convergencia, -en que el arco apunta más allá del blanco-. Entre el límite y lo que está limitado, la relación es de homógonos. Este término permite comprender en el campo poético cómo el reposo es límite del movimiento, etcétera. Lógicamente esta teoría del paso al límite suspende la jurisdicción del principio del tercero excluido y matemáticamente introduce consideraciones que escapan en cierto modo de la métrica ((Díaz 2008:251).

Expectrovertidamente, el poema sólo aparece a través de sus metamorfosis o en la declinación de sus perfiles. Así como la figura geométrica, para Leibniz, era el ser una unidad vista en la perspectiva de una serie infinita de términos componentes, como sucede con la punta del cono que es el punto de vista al que se refiere el círculo, la elipse, la parábola, la hipérbola, etc.

El carácter expectrovertido del cono se reconoce en el símbolo de la cúpula negra, "montadura aparente, sabia superposición de estructuras estrelladas donde, preciosa, ha quedado engarzada la luz"(Sarduy1974b:20).

En las cónicas, no hay un punto de vista al que exportaría la elipse, y otro para la parábola y otro para el círculo. El punto de vista, el vértice del cono, es la expectroversión o condición bajo la cual se capta el conjunto de la variación de las formas o la serie de las curvas del segundo grado. La cúpula como el cono guarda toda la serie de las luces y las sombras, hace aparecer la conexión de todos los perfiles entre sí, la serie de todas las curvaturas o desviaciones.

La expectroversión de las cónicas metaforiza lo efímero, la repetición, el travestismoy la conectividad que, se dan en las frases de Big Bang en cuanto sistema relacional que nos recuerda las Ciudades Invisibles:

[...] los habitantes tienden hilos entre los ángulos de las casas, blancos o negros o grises o blanquinegros, [...]. Cuando los hilos son tantos que ya no se puede pasar por en medio, los habitantes se marchan: las casas sedesmontan; quedan sólo los hilos y los soportes de los hilos.

[...] Vuelven a edificar Ersilia en otra parte. Tejen con los hilos una figura similar que quisieran más complicada y al mismo tiempo más regular que la otra. Después la abandonan y se trasladan aún más lejos con sus casas (Calvino 1998:90).

Esta lógica diagramática se corresponde con la escritura como épure, construcción geométrica que implica lo local. Se trata de proyecciones y decantaciones, dibujos/ purgaciones; trazos/refinamientos.

La escritura como épure es un proceso exponencial y de supresión que se refiere en geometría descriptiva al gesto de hacer proyecciones en el plano de un objeto que se halla en el espacio, no representado en su totalidad, del que se conoce solamente un perfil arbitrario, parcial: 
[...]A cada movimiento de la mano, a cada nueva página la escritura aparece sobre las cenefas, entre las piedras rojas y otra vez sobre el muro,

del muro donde el mapa de la página anterior acaba de borrarse, los signos descendiendo hacia la arena, brasas (Sarduy 1974a: 11).

La escritura como épure sigue el surgimiento de la forma y el viento del vacío. Incluye una estética de la evanescencia, "El mundo se va borrando, se ausenta y, desde atrás, retraído, se crea un lenguaje hipotético, leve, espectral [...]. Así comprendemos la relación entre la forma y la nada, el doble valor de la exactitud que nos recuerda el contraste mallarmeano entre el contenido inmaterial y la forma ceñida, delimitada" (Díaz 2010: 30).

Lo evanescente se absorbe en las redes de lo invisible, los pliegues de la épure, las envolturas indivisibles de las distancias o el continuo metonímico de los estratos verbales. El punto de vista en Sarduy es el doble foco de las cosas, la determinación de lo indeterminado por signos ambiguos: un triángulo de estratos.

Pasamos del continuo de lo diagramático a la noche de lo geológico, al foco de curvatura (del lado cóncavo), sumergido el cuerpo, del envolvimiento de la voz al pliegue de la luz, a la inclusión, a los intersticios de la sombra, a la idea de diferencial (Díaz 2008: 256).

La idea de diferencial en Leibniz fue producto de su observación de la naturaleza, en cuyos pliegues infinitos previó diversos grados de diferenciabilidad y distintos órdenes de infinitud. En la Monadología podemos sentir la potencialidad ilimitada de lo singular, el entrelazamiento de sus infinitos interceptados o envueltos en la tesitura de un infinito más sutil ${ }^{16}$ :

Cada porción de la materia puede ser concebida como un jardín lleno de plantas y como un Estanque lleno de peces. Pero cada rama de la planta, cada miembro del Animal, cada gota de sus humores es, a su vez, un jardín o un estanque igual que los primeros.

$\mathrm{Y}$, aunque la tierra y el aire interpuestos entre las plantas del jardín o el agua interpuesta entre los peces del estanque no son planta ni pez, contienen, sin embargo, todavía plantas y peces, si bien de una sutilidad la mayoría de las veces imperceptible para nosotros (Leibniz 1981: 133-135).

\footnotetext{
${ }^{16}$ Según explica L. Brunschvicg: "La sabiduría divina, explicaba Leibniz, va mucho más allá de las combinaciones finitas que podemos hallar en la realidad; las convierte en una infinidad de infinitos, esto es, en una infinidad de sucesiones posibles del Universo, cada una de las cuales contiene una infinitud de criaturas"(Citado en Zellini,133).
} 
Encontramos aquí la idea de un continuo, el valor lógico de la inclusión, el valor literario del perspectivismo, y en los intersticios localizamos los mecanismos de las combinaciones de lo posible, es decir, los diferenciales que podemos comparar con la palabra poética:

A cada cuerda /tiembla la superficie, a cada voz en el rectángulo de la alberca se desplaza /un instante la sucesión de arcos, de salas que se abren al jardín, de jardines /idénticos que interrumpen albercas, rectángulos espejeantes, agua inmóvil /donde a cada voz, a cada cuerda se reflejan un instante (Sarduy1974a: 9).

Tenemos en este fragmento la curva continua de la arquitectura barroca, las tangentes sonoras $c a, c o, c u ; c a d a$, arcos, cuerda, albercay sus sentidos, que manifiestan el carácter de lo diferencial en las palabras, en acepción leibniciana, en cuanto fuerzas instantáneas de la realidad infinitamente sutil, variaciones en estado germinal que están en los pliegues de las ordenaciones, movimientos que anticipan invisiblemente el impulso de la forma. Los diferenciales guardan una potencialidad y concentración ilimitadas para hacer posibles las transformaciones; tal como sugiere la idea propuesta geométricamente por Leibniz, de una "especie de fuerza primitiva, de una esencia invisible de la que se pudieran deducir los efectos de la apariencia ordinaria de los fenómenos"17. Así en los intersticios más finos de la ordenación del poema intervienen esos mecanismos de transformación de la realidad, de realización de lo posible. Son aprehendidos, en las palabras, en su hallarse al frente de un estado de vacuidad en el que se encierra el máximo de potencialidad ilimitada unida a la máxima concentración de entelequia, de esencia delimitadora. Expectrovertidamente el poema trasmite sus metamorfosis por esos elementos fulgurantes, espectrales, ecos, sombras. Sus palabras serían, metafóricamente, diferenciales que son infinitesimales, cantidades evanescentes, inasignables, que pueden estar organizadas según órdenes incomparables a los que se puede aplicar la operación del paso al límite. Desde el marco leibniciano podemos esbozar el principio de que en la poesía de Sarduy se da una constante modulación infinitesimal de los límites verbales,

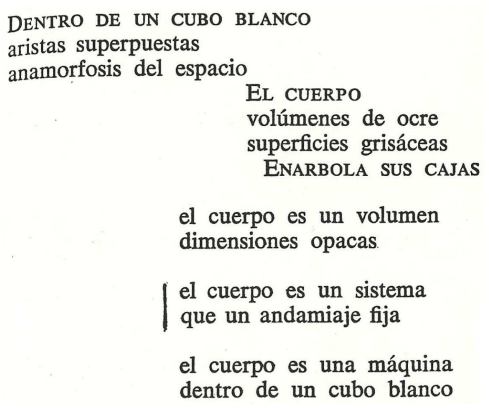

(Sarduy 1974a: 19).

La intratextualidad, la escritura entre la escritura se relaciona a tipos de perspectiva extrema como la anamorfosis que ofrecen los fonemas a lecturas espectrales y fluctuantes. En la anamorfosis se produce una transposición de formas y el forzado desplaza-

\footnotetext{
${ }^{17}$ Vid. el desarrollo de esta idea en Zellini, Paolo, 133.
} 
miento del espectador, según Sarduy, este procedimiento impugna la forma con la imagen última de la nada, la muerte:

A través de la anamorfosis, la pintura puede dar a ver (con una inquietante cercanía, enmascarándola en una forma falaz, suspendida sobre el suelo y en primer plano), la imagen última, esa que no se percibe más que cuando el sujeto que se va -le sujet qui se barre-, ya al abandonar la pieza en que se encuentra la representación, desilusionado y sin esperanzas de comprender el jeroglífico de nácar, como para despedirse, mira hacia su izquierda, mira hacia la siniestra, y como en un rebus analítico, es precisamente a ella, a la Siniestra, en el esplendor macabro de su blasón óseo, a la que descubre tronando ante las medidas terrestres -la Perspectiva y la Música- y celestes -la Astronomía-: reidora en el primer plano, la Toda-Hueso avanza escindiendo la mirada final del espectador (Sarduy 1982: 29)

La perspectiva puede ser una habilidad difícil, pero su base, descansa sobre un simple e incontrovertible hecho de experiencia, el hecho de que no podemos con la mirada torcer una esquina. A causa de esta incapacidad, mientras miramos con un ojo estacionario vemos los objetos sólo por un lado, y tenemos que adivinar o imaginar lo que está detrás, pues las percepciones no son revelaciones. Lo que podemos ver por un agujero no nos revela inmediatamente "lo que hay allí"; en realidad, es absolutamente imposible que distingamos lo que hay allí; sólo podemos adivinar, y nuestras conjeturas vendrán influidas por nuestras anticipaciones.

La ambigüedad inherente de todas las imágenes nos recuerda una de las razones por las que tan raramente tenemos conciencia de ella. La ambigüedad, no puede nunca ser vista en cuanto tal. Sólo nos fijamos en ella cuando aprendemos a pasar de una lectura a otra, y al advertir que ambas interpretaciones encajan igualmente bien con la imagen, "DENTRO DE UN CUBO BLANCO/ aristas superpuestas/ anamorfosis del espacio". Cualquier disposición oblicua o curvilínea que cuide el cruce de sus puntos nodales producirá el mismo aspecto desde un punto de vista, "el cuerpo es una máquina/ dentro de un cubo blanco".

La perspectiva es pues la geometría necesaria para nuestra construcción y el término técnico para las imágenes oblicuas y curvas que cumplen aquella condición es anamorfosis. Desde un punto de vista fijo, cualquier deformación en perspectiva puede hacerse indiscernible de la imagen normal. Se llama deformación porque no es un modelo relacional. Esta deformación forma otras posibles constelaciones de sentido, "EL CUERPO/ volúmenes de ocre/ superficies grisáceas/ ENARBOLA SUS CAJAS”.

Doble carácter de la anamorfosis, infiniversión, en donde la evasión implica un regreso; la imagen, ahogada en un torrente o en un torbellino confuso, emerge semejante a sí misma es una visión oblicua o reflejada en un espejo, "el cuerpo es un sistema/ que un andamiaje fija". La destrucción de la figura precede a su representación.

Como las cajitas catóptricas de Kircher, las poesías aparecen como teatros que multiplican y trasponen las formas. Sustituyen una imagen por otra, el cuerpo por una máquina, por un cubo, etc; un hombre por una mujer, por un animal o por escombros. Cajas catóptricas donde las figuras dilatadas se reconstruyen al reflejarse en un cilindro $\mathrm{o}$ en un cono. El doble espejo cilíndrico en $\mathrm{S}$ hace inaprensibles todas las cosas, los objetos se transfiguran en él a medida que se acercan a su superficie, "EL CUERPO/ volúmenes de ocre/ superficies grisáceas/ ENARBOLA SUS CAJAS". Cambian tanto en las partes convexas como en las cóncavas: la imagen reflejada en la masa larga se asemeja a un río. 
Escorzo. Las imágenes giran unas sobre las otras. El gris atraviesa la diagonal de la forma. El soporte crea el andamiaje: la inestabilidad de un equilibrio a punto de romperse para rehacerse de nuevo. Superficies que se dilatan o quiebran. Formas evanescentes, curvas y espirales, "DENTRO DE UN CUBO BLANCO/ aristas superpuestas/ anamorfosis del espacio /// el cuerpo es una máquina/ dentro de un cubo blanco." La movilidad de la obra exige del lector, a su vez, se deslice y multiplique los puntos de vista. Las palabras se deslizan unas sobre otras en un mándala circular y en espiral que, sirve al propósito creador de dar expresión y forma a algo que aún no existe, algo que es nuevo y único. El proceso de la espiral ascendente va hacia arriba mientras, simultáneamente, vuelve una y otra vez al mismo punto, infinivertidamente, la espiral escribe, es un círculo remitido al infinito, un lenguaje haciéndose de modo continuo: escritura.

Sobre la espiral, las cosas retornan, pero a otro nivel: "el cuerpo es un volumen / dimensiones opacas". Nada sucede por primera vez y, no obstante, todo es nuevo. Como los signos de la lengua son muy limitados y la combinatoria es infinitamente libre, la novedad consiste en repeticiones muy próximas, "el cuerpo es una máquina / dentro de un cubo blanco". De la misma manera, las otras composiciones de Sarduy, a base de espirales estallan en todas las direcciones a partir de un elemento repetido y desplazado; las espirales aliadas a vacíos, tachaduras o superposiciones, crean de manera explosiva la frase poética.

La espiral quizá sea la figura que mejor vincula al vacío: serpentea indefinida hasta retornar a la nada, fluye siempre más lejos, regresando, infinivertidamente al origen. En general, las distintas variantes de la anamorfosis representan el juego de la condensación y encuentran nuevas posibilidades con la incorporación del movimiento (de modo similar a la pintura cinética o el cine). El desplazamiento del espectador condensa todas las unidades plásticas en un último elemento geométricamente abierto.

Conciencia de otro espacio ficticio donde la plasticidad de las palabras acentúa su forma espacial de existencia, como en el manierismo se une una tendencia a la profundidad con una tendencia a la superficie. Los espacios internos a su vez aparecen organizados de modo diverso, en espacios locales donde se aglomeran en una esquina las palabras, caen o se pierden en campos ilimitados, indefinidos, con fronteras elásticas que construyen laberintos inestables, puentes fugaces que arrastran un ciclo de transformaciones:

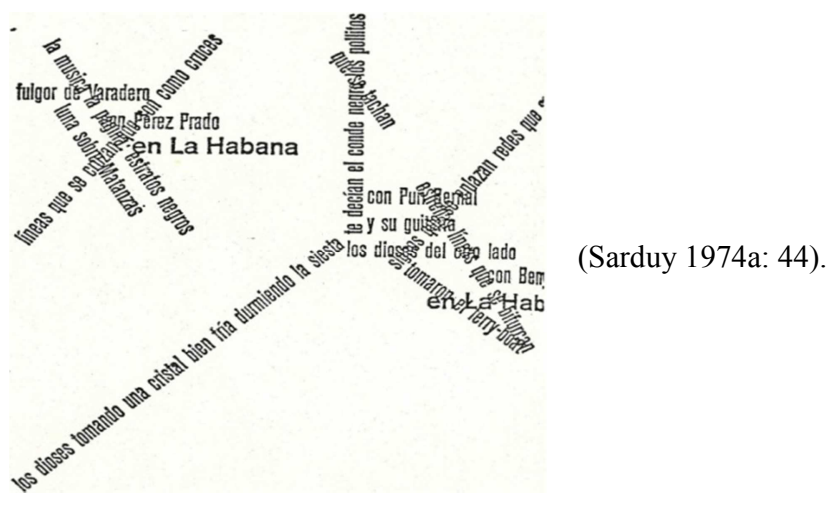


La imagen resucita de su tumba de líneas. La anamorfosis representa y esconde al objeto mismo que representa. Vértigo, nada es más constante que la inestabilidad misma, la existencia sólo se experimenta en la fuga, convirtiéndose en otro. Lecturas radiales de una imagen difusa y rota. Meditación sin soporte, infiniversión del desciframiento, lectura barroca en la que "sólo cuenta la energía de conversión y la astucia en el desciframiento del reverso - el otro de la representación -; la pulsión de simulacro que en [el famoso cuadro] Los Embajadores, emblemáticamente, se desenmascara y resuelve en la muerte" (Sarduy 1982:27).

El desplazamiento del lector en la anamorfosis descubre una figura bajo la aparente amalgama de colores, sombras y trazos sin concierto. La verdad barroca de este procedimiento está, según Sarduy, en la "reducción a su propio mecanismo técnico, a la teatralidad de la simulación" (1982: 25), el cuerpo es una máquina/ dentro de un cubo blanco. Ausencia de lo nombrado, tachadura del exterior invisible que el cubo organiza como reflejo. Tautología emblemática del barroco: la poesía se encuentra en la poesía: la poesía y la no-poesía: la propia poesía citada, que, de la representación, no muestra más que la armadura, el soporte.

Lenguaje barroco, reelaborado por el doble trabajo elidente, desdoblamiento y supresión. Denegación de un elemento y concentración metonímica de la luz en otro. Organización de la carencia donde algo se pierde o cae del lenguaje. Espacio abierto que implica la fuga de un objeto de pulsión. En la cadena los términos elididos son pocos: aquellos "representantes de la representación" ligados, directamente o no, a ciertas pulsiones como la muerte.

El vacío se trasviste en pura energía. A partir de esa nada se hace más intensa la teatralidad de las formas. En este saber sobre la nada la experiencia del poeta confluye con la experiencia del místico ya sea de Oriente o de Occidente. En la tradición Oriental, predomina el principio taoísta de la Gran Nada Primordial y la noción budista de sûnyâta, vacuidad o vacío o nada absoluta. La lógica del sûnyâta alude al vacío como presencia pura. Es meditación sin objeto, el vacío total como última realidad. La realidad es vacuidad y su carencia de forma origina la manifestación, como lo precisa $\mathrm{K}$. Nishitani: "La vacuidad es la forma real de la realidad. La forma real como tal es sin forma. Sólo en esta no-forma un hecho llega a manifestarse como tal"(1999: 127), barcas vacias/ bajando/por canales blanco.

El vacío es la forma y la forma es el vacío, tanto en el budismo como en los poemas de Sarduy y,como en nuestro modelo infinivertido, en el que los signos son pulverizados, la realidad se disuelve y entramos en la transparencia,

\section{Y nada.}

El vuelo.

Y nadie.

\section{Referencias biliográficas}

BARROS, Tomás (2001):Ritmo y abstracción. A Coruña: Edicios do castro.

BARTHES, Roland (1973): Ensayos Críticos. Barcelona: Seix-Barral

CALVINO, Italo (1998):La Ciudades Invisibles. Madrid: Siruela.

COSTA, Horacio (1991): "Sarduy: la escritura como épure". Revista Iberoamericana. Vol. LVII, Núm. 154: 275-300

CHENG, Francois (1993): Vacio y Plenitud. Madrid: Ediciones Siruela. 
DELEUZE, Gilles (1989):El Pliegue. Barcelona: ediciones Paidós.

DÍAZ GAMBOA, Sandra (2008):La experiencia de los límites en la obra de José Ángel Valente y sus "implicaciones” lógico-matemáticas, 2 v. [Tesis Doctoral]. Madrid: Universidad Nacional de Educación a Distancia, Facultad de Filología. (2009): "La formación de conceptos poético-matemáticos en la obra de José Ángel Valente”. SERTA. Revista Iberorrománica. Poesía y Pensamiento Poético, 10: 56-80. (2010): "La Estética de la Evanescencia” en Blanco de Octavio Paz. [Tesis de Maestría en Literatura]. Bogotá: Facultad de Ciencias Sociales. Pontificia Universidad Javeriana.

GENETTE, Gerard (1989):Palimpsestos : la literarura en segundo grado. Traducción de Celia Fernández Prieto. Madrid: Taurus.

JAKOBSON, Roman (1981):Lingüística, poética, tiempo. Conversaciones con Krystina Pomorska. Barcelona:Crítica.

KLINE, Morris (1992): El pensamiento matemático de la Antigüedad a nuestros días. V. III. Madrid: Alianza Editorial.

LAO ZI (2003):Tao te King. Madrid: Editorial Siruela.

LEIBNIZ G.W. (1982): Escritos Filosóficos. Buenos Aires: Editorial Charcas. (1981): Monadología. Oviedo: Clásicos el Basilisco, Pentalfa Ediciones.

NEWMAN, James R., (Editor) (1983):SIGMA. El mundo de las Matemáticas. Vol. 5. Barcelona: Ediciones Grijalbo.

NISHITANI, Keiji (1999):La Religión y la nada. Madrid: Ediciones Siruela.

PAZ, Octavio (1987):Los hijos del limo. Barcelona:Editorial Seix Barral.

PENROSE, Roger (1995):La nueva mente del emperador. Traducción de Javier García Sanz. Barcelona: Grijalbo Mondadori.

SARDUY, Severo (1974a):Big Bang. Barcelona: Tusquets. (1974b):Barroco. Buenos Aires: Editorial Sudamericana. (1982):La Simulación. Venezuela: Monte Ávila Editores.

SERRES, Michel (1996):La comunicación, La comunicación. Hermes I.Barcelona: Editorial Anthropos.

ZALAMEA, Fernando (1998):Signos Triádicos, Signos Triádicos. Nueve estudios de caso latinoamericanos en el cruce Matemáticas- Estética - Lógica. Bogotá:Ministerio de Cultura, Programa de Becas Nacionales Ariadna y Penélope (2004): Redes y mixturas en el mundo contemporáneo, Ariadna y Penélope. Redes y mixturas en el mundo contemporáneo. Oviedo: Ediciones Nobel.

ZELLINI, Paolo (1991):Breve historia del infinito. Madrid: Ediciones Siruela. 